\title{
DISCOVERING THE TRUTH OF COVID 19 AND OTHER CONTAGIOUS DISEASES BY APPLICATION OF THE THEORY OF CHANGES AND THE THEORY OF YIN YANG
}

\author{
Cheok Wee Teck ${ }^{1^{*}}$, Cheok Yean Chin ${ }^{2 *}$
}

${ }^{1}$ Inti International University of Malaysia, FHLS Department-TCM centre

${ }^{2}$ University of Putra Malaysia (UPM)-Nutritionist Department

Received - July 18, 2020; Revision - September 17, 2020; Accepted - November 9, 2020

Available Online - March, 252021

DOI: http://dx.doi.org/10.18006/2021.9(Spl-1-GCSGD_2020).S30.S37

Keywords
Covid 19
Contagious Diseases
Microorganism
Decomposition
Mother Earth
Equilibrium
The Theory of Changes

\begin{abstract}
The current pandemic COVID-19 continues to spread rapidly around the world. Many countries are still at the peak of infection. The prolonged lockdown has caused a serious impact on the socio-economy of the whole world. There is a growing concern about the link between animal's based food product with all the contagious diseases as most of the pandemic are initiated from farming animals. The micro study of the virus or bacteria could trace the infectious pathway of the contagious diseases and find substantial problemsolving solutions. Nevertheless, the root cause of the diseases remained unknown. Because of this, it is essential to evaluate the root cause of the disease in the macro-scope of study. By discovering the designated function of all the microorganisms from the insight perspective of the Theory of Changes and other Taoism theories, we could define the effective problem-solving solution. The result of the finding has discovered that the microorganisms which bring the so called "contagious diseases" are the cure for Mother Nature to resume its equilibrium. They are the agents of decomposition and transformation of Mother Nature. Coronavirus, other viruses, and bacteria are the essential microorganisms being created by nature to decompose the excessive animals' dead bodies that awash in the environment into smaller particles or subtracts, transforming them into useful nutrients to be absorbed and restored by Mother earth. After identifying the deadly microorganism as the cure for Mother Nature and recognizing the harm that we have done to Mother Nature, we could find out the root cause of the problem and solve the problem fundamentally.
\end{abstract}

* Corresponding authors

E-mail: weeteck.cheok@newinti.edu.my (Cheok Wee Teck); setiatcm@gmail.com (Cheok Yean Chin )

Peer review under responsibility of Journal of Experimental Biology and Agricultural Sciences.

Production and Hosting by Horizon Publisher India [HPI] (http://www.horizonpublisherindia.in/).

All rights reserved.
All the articles published by Journal of Experimental Biology and Agricultural Sciencesare licensed under a Creative Commons Attribution-NonCommercial 4.0 International License Based on a work at www.jebas.org.

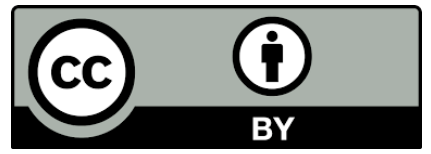




\section{Introduction}

The Novel Coronavirus "Covid 19" which occurred at the end of 2019 has initiated a pandemic. Although the exact origin of SARSCoV-2, the etiologic agent of COVID-19, is currently unknown, there is substantial evidence to suggest the source of transmission of the virus occurred within the Wuhan wet market. In these markets, bats and wild animals are frequently sold and stored in close contact (Alonso Aguirre et al, 2020). Besides Covid 19, there are several diseases well known to both the industry and the general public that are directly related to all the domestic meat species of beef, pork, lamb, and poultry. These include BSE (bovine spongiform encephalitis) from beef cattle, Trichinosis and H1N1 from pork, Salmonella and Avian Influenza from poultry, Scrapie from lamb and mutton, Foot-and-mouth disease from livestock, and many others. These are known as zoonotic diseases or zoonoses (Centers for Disease Control and Prevention, 2017). There is a growing concern about the link between animal's based food products with all the contagious diseases.

This research is to identify the link between meat production and consumption with the Covid 19 and other contagious diseases, discover and evaluate their root cause from the perspective of The Theory of Changes and other Taoism theories, with the aims of defining the effective problem-solving solution. The discovery of 8

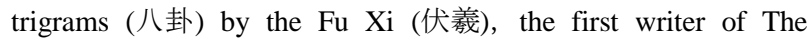
Theory of Changes was based on the observation of all the phenomenon in the universe (Liang Yong Xuan \& Lu Zhao Lin, 2005). In light of this, the observation of the phenomenon from the macro but insight perspective could help us to discover the truth of the contagious disease and provide us a better solution and prevention. This research will focus on the macro analysis of the natural setting of Heaven and Earth by using The Theory of Changes and other Taoism theories.

\section{Discussion}

Most of the recent researches are focusing on the micro study of the microorganism and identifying them as pathogenic factors. This study is based on a macro study on the microorganism to explore the true identity and function of the so-call life-threatening microorganism. Based on the great observation and justification by the Theory of Changes, findings of this study has proven that all the microorganism inclusive of Covid 19 are the important elements in the Mother Earth for decomposition and transformation settlements.

It provides a revolutionary perspective of microorganisms and rectifies the common wrong perspective on deadly viruses and bacteria. The human could only obtain their absolute solution in solving the threat of Covid 19 and other contagious diseases by identifying the true identity and function of the microorganism.
Excessive meat consumption and meat production not only harm innocent lives, affect the health of the public but also causing a detrimental effect on the earth. The existence of a huge amount of livestock, farming animals either land or aquatic and the leftover animals' dead bodies generated from the meat consumption have made our living, working and social environment disgustingly filthy. The methane created by livestock has proven to be the major cause of global warming in the world.

According to research, more than 200 million land animals are killed for food around the world every day. That comes out to 72 billion land animals killed for food around the world every year. Including wild caught and farmed fishes, we get a daily total of closer to 3 billion animals killed (Matthew Zampa, 2018). Compare to merely 7.8 billion world population (Kaneda et al, 2020), this amount of death is comparatively huge. It is generally believed that pests, insects, and microorganisms are the primary cause of the diseases. When the living and working environment of the human being are awash with the uneaten animals' dead bodies like the organs, skins, heads, and other inedible parts. It has provided a conducive breeding and living environment for bacteria, viruses, and other pathogenic factors.

《Plain Question. Liu Wei Zhi Da Lun》 in Yellow Emperor Classic has stated: "Excessive is destructive, it should be neutralized to the moderate and right order." (《素问。六微旨大论》：“六则害, 承乃治。”) (Wang Qi Qing, 2003). The bigger destruction should be counteracted by the bigger neutralizer. The amount of livestock raised and animals killed is excessive. This should be withstood and neutralized to the right and moderate order before disastrous consequences happen. As a result, nature is carrying out the necessary settlements to purify the environment and restore the ecological balance.

Animals' dead bodies and excrement need to go through the decomposition process. They are broken into smaller parts for the earth and nature to absorb and dissolve. The earth has the function of transforming all the waste into usable elements. The earth has the characteristic of Kun (坤). According to Theory of Changes

《Zhou Yi 》 : "Earth is represented by Kun, thus the superior man should possess the great moral of tolerance and care for all living beings”. (《周易》：“地势坤, 君子以厚德载物” ) (Yang Li, 2010).

The earth with the characteristic of loving kindness has the great contribution and devotion of accepting, carrying, and holding, preserving, sustaining, nourishing, and growing all things. It could accept the energy yang (solar energy) and at the same time tolerate the turbid and rubbish. Those who want to practice and cultivate the Dao or achieve superiority should learn from the earth. With her great tolerance, mother earth is willing to accept and hold all 
objects lying upon her. Besides this, she is also willing to nourish the good and transforming the bad. The two major devotions and functions of Mother earth are "Nourishing and Transforming". It could have resembled the mother who is feeding her children with her breast milk and cleaning all excrements and urine discharged by her children. The Great Mother characteristic of the earth has been generally recognized and claimed by most of the people in the world. Thus, we usually call the earth as Mother Earth.

The functional characteristic of Kun could be explained better by the following two statements in the Theory of Changes 《Kun Hexagram. Explanation of Hexagram 》 stated that: "Yuan, Heng, Li, Pin Ma, Zhen” (《坤卦卦辞》所言 : “元, 亨,利,牛马, 贞) While the 《Qian Hexagram. Explanation of Hexagram 》 stated: “ Qian, Yuan, Heng, Li, Zhen.” (《乾卦卦辞》原文所说：“乾，元，亨，利，贞”) (Yang Li, 2010). The first statement is explaining the characteristics of Earth "Kun"(坤), while the second statement is explaining the characteristic of Heaven “Qian” (乾) . Earth “Kun” (坤) is Yin, Heaven "Qian" (乾) is Yang. The function of the Kun could only be accomplished when there is an involvement of the Qian. The holy integration in between the Heaven "Qian" (乾) and Earth “Kun” (坤) (乾坤合德) or integration of Yin and Yang could generate a living environment which could sustain and nourish all the living beings.

They both accomplished the four processes together which are Yuan, Heng, Li, Zhen (元, 亨, 利, 贞). Before they could accomplish these, the Heaven should resume his Qian (乾) status, while the Earth should restore to Pin Ma 牝马condition. Qian represents the Heaven, the movement of Heaven "Qian” (乾) is powerful and ever vigorous. Yuan (元) is the original qi or energy yang (solar energy) generated by the Heaven “Qian” (乾) to contribute to the Earth “Kun”(坤). Yuan (元) should be conceived by the Earth to nourish the plants and other creation lying upon her. Heng (亨) always be pronounced in the complete words call Heng Tong (亨通) which means proceed smoothly and prosperously. This is the result of the driving force of the energy Yang. Li (利) means benefiting. It means the Original Qi which is proceeding smoothly and prosperously could benefit the earth and all the living being. $\mathrm{Li}$ also could be explained as Yi (宜) which means a conducive living environment which could sustain all living being. The most conducive and sustainable living environment is the Consolidated Yang and Harmonized Yin (阴平阳秘) condition where the Yang is consolidated and restored firmly underneath the harmonized Yin. This condition is the most favorable condition which could be benefiting all the living being. Zhen (贞) means right and correct. To achieve a sustainable living environment or we call it Consolidated Yang and Harmonized Yin, everything should be in the correct and right pathway, or other more profound words, and the entire natural phenomenon should achieve equilibrium and strive for ecological balance.

As previously mentioned before the environment and ecological balance of this planet have been damaged by the farming industries and the wrong food consumption habit generally possesses by the majority of people of the world. The Earth "Kun" (坤) need to resume it by applying the Pin Ma (牝马) process. Pin (牝) means female, ma (马) means horse. Pin Ma (牝马) means female horse. The explanation of Hexagram is written by The King of Zhou Wen (周文王) of the Zhou Dynasty (周朝). Female possesses the Earth “Kun” (坤) characteristic. Kun (坤) major characteristics and functions are growing and transforming. Female animals and other creatures could procreate animals' offspring. To procreate they need the involvement of male animals and male creatures.

All the living beings on this planet are created by the nature with holy duties. They should accomplish their tasks to help the mother earth and father heaven to accomplish the process of sprouting (生), growing (长), transforming (化), harvesting (收) and restoring (藏). In other words, they should work hand in hand to ensure the process of Yuan, Heng, Li, Zhen (元, 亨, 利, 贞) are running smoothly. These creatures are inclusive of all types of animals, insects, and microorganisms.

The King of Zhou Wen (周文王) of the Zhou Dynasty (周朝) used the horse to represent all animals and creatures probably because horses are the main transport for the peoples in ancient period, or in other words, horses are the most intimate friend for the human being. Besides that, all writing information in ancient times had to be carved on stone, bones, or bamboo. The record of the information could not be too lengthy. It should be short and precise. The readers should extend the meaning of one word by using logical and critical thinking. Thus, the usage of Pin Ma (牝马) was referred to all the living beings in nature.

As it is known that some creatures are good at spreading the seeds like the birds, bees, and certain insects. Most of the animals dropping and excrement could become the fertile fertilizers and nutrients for the mother earth and they are helping the growth of the trees and plants. The green coverage of plants has provided a Harmonized Yin on earth which could conceive the Consolidated Yang better. Certain animals are ensuring the health of the plants and controlling other animals.

Herbivores are eating grasses and leaves. They help to trim the plants to ensure the greenery of the plants. Some animals like lions, tigers, leopards, and other carnivores which are at the top of the food chain are controlling the numbers of other animals to avoid excessive conditions happen. They are "harvesting" the 
excessive and unnecessary. After the animals were killed, nature would ensure all these animals' dead bodies with awful and disgusting smells are cleaned up properly. The leftover animals dead bodies need to be decomposed into smaller particles for the earth to absorb and restore. To accomplish this, nature has created different types of scavengers or partial scavengers like raccoon, rat, coyote, opossum, Tasmania devil, hyenas, wild dogs, wolf, wolverine, lizards, Comodo dragon, vulture, condor, Hagfish, Black Hagfish, Feeder Shrimp and many others which are munching on the dead bodies.

In addition to these, nature has created different types of insects and worms like cockroaches, meat ants, fire ants, flies, burying beetles, tapeworms, earthworms, maggots, or even certain smaller microorganism like bacteria and viruses to fasten the decomposition process. They are helping the dead bodies to decompose and nutrients could be taken from dead bodies to the earth through the soil that is enriched with their excrement or castings. At last, all the dead bodies will be dissolved properly and being absorbed completely by the earth. They are performing the Pin Ma (牝马) duties. All in all, these animals and creatures are helping in the transforming, harvesting, and restoring process for the sole purpose of achieving Zhen (贞) where the $\mathrm{Li}$ (利)and $\mathrm{Yi}$ (宜) living environments are maintained properly. The Consolidated Yang and Harmonized Yin (阴平阳秘) condition of the mother earth could be sustained.

All the scavengers, certain insects, worms, and microorganisms are created by nature to decompose the animals' dead bodies into smaller particles or subtracts. It could be transformed into useful nutrients to be absorbed and restored by the earth. The data analysis by the article with the title: "Virus decomposition provides an important contribution to benthic deep-sea ecosystem functioning." indicate that the decomposition of viruses provides an important, previously ignored contribution to deep-sea ecosystem functioning and has an important role in nutrient cycling within the largest ecosystem of the biosphere (Dell'Anno et al., 2015). Research on Arbuscular mycorrhizal fungi has also proven that their existence is playing an important role in litter decomposition (Xiongshi Kong et al, 2018). Another research also revealed that the Thraustochytrids are cosmopolitan osmotrophic or heterotrophic microorganism that are considered as important decomposers in coastal ecosystems (Yoshitake Takao et al., 2015).

Good quality and effective subtractive system are vital to ensure the growth of the healthy and thriving plants. This is essential in creating a harmonized Yin and balance natural ecosystem. The plants could emancipate oxygen in to the air and absorb carbon dioxide making the environment habitable for living beings. This is essential in creating a harmonized Yin and balance the natural ecosystem. The plants could emancipate oxygen into the air and absorb carbon dioxide making the environment habitable for living beings. A good subtractive system is not only providing nutrients needed by the plants but also creating an environment that encourages and promotes the colonization of even more bacteria, viruses, and other microorganisms in the earth.

These additional microorganisms are necessary to break down the toxic waste substances remaining in the dead bodies' components, turn them into harmless nutrients that can be absorbed by the plants. Some bacteria and viruses could even improve filtration and purification of air, water, and soil making clearer air, water, and soil condition which could counteract the air, water, and soil pollution created by the animals' dead bodies. At last, a healthier and longer-lasting living environment which is fulfilling the Zhen condition was made perfectly.

By understanding the true meaning of the Theory of Changes, we realized that the existence of all the contagious diseases either the bacteria in the Black Death or viruses in the Covid 19, SARS, MERS, and Ebola are the essential microorganisms being created by nature to decompose the animals' dead bodies into the smaller particles or subtracts. By doing so, they could filter and purify the air, water, and soil. The more animals' dead bodies are created by the human being, the more powerful and lethal the microorganism will be generated by Mother nature to counteract the problem. As mentioned before that the Yellow Emperor Classic had stated: "Excessive is destructive, it should be neutralized to the moderate and right order" (《素问。六微旨大论》：“六则害, 承乃治。”) (Wang Qi Qing, 2003). The bigger destruction should be counteracted by the bigger neutralizer.

Human are not the natural carnivores and scavengers but pretend to eat like them, their internal body parts will be dissolved and decomposed by these microorganisms as well. All these microorganisms which supposed to be in the digestive system of the scavengers now exist in our digestive system. As human bodies are different from the structure of the carnivores and scavengers. Our digestive systems are not designed to counteract the adverse condition. Low acidic conditions in our stomach could not kill the microorganism and control their colonization. In order words, they are the suitable Pin Ma (牝马) agents to accomplish the decomposition and transformation process, but we are not.

The same microorganisms which are benefiting the scavengers and carnivores would become harmful to us. All these microorganisms are like flies which are very sensitive to the awful and disgusting smell of dead bodies. They will be attracted to those things which have an awful and disgusting smell or even transformed by themselves as colonization could be promoted in the right environment. 
If we consumed plenty of meat (animals' dead bodies), definitely we would attract or generate all these deadly bacteria and viruses which could cause life threatening diseases. The capability of selfgeneration and self-transformation of the microorganisms could explain why some Covid 19 cases which have no contact with the pandemic area are infected out of no way. This could be the direction that the scientist should further their investigation for that unknown etiological pathway like the first 15 cases Covid 19in Italy which had no travel records to China (News Strait Times, 2020).

The Covid 19 cases happen in Esther Island which is located far from the Chili mainland where the community is in isolation. The first person who contracted Covid 19 in Esther Island is a Chilean woman who had not been overseas or to be in contact with any foreigner (RNZ News, 2020). Although the current studies have defined the pathophysiological characteristics of Covid 19, there is great uncertainty regarding its mechanism of spread. This review could provide some clues in finding the reason.

The existence of viruses, bacteria, and other microorganisms in the decomposition process of turbid, waste, dead bodies, and other organic materials could be excessive as well. As what have mentioned before: "Excessive is destructive." Nature needs to generate some elements to counteract them. As a result, some other microorganisms or natural substances will be generated by Mother Earth to neutralize the excessive to achieve equilibrium. Investigation of anti-HIV properties of oxihumate has shown that coal-derived humid acids and oxyfulvic acid, which are complex mixtures formed during the decomposition of organic matter including cellulose found naturally have been previously shown to have anti-HIV properties (Van Rensburg et al., 2000; Van Rensburg et al., 2002). The occurrence of the cure for HIV or antiHIV properties in the decomposition process in nature has proven that the contagious HIV viruses are existing in the decomposition process as well in Mother earth.

The excessive HIV existence has generated anti-HIV properties. Besides that, these properties can be predicted to be effective against influenza but that remains to be proven (Kotwal, 2008). In short, all the relevant researches above have shown the complex counter-reaction process of the decomposition settlements of Mother Earth. The purpose of this reaction is to ensure the equilibrium of the ecosystem.

Scientists understand that the Black Death which struck Europe and Asia in the mid-1300s was spread by a bacillus called Yersina pestis, which lives in rodents. Rodents have developed immunity towards these bacteria, but not the fleas that feed on their blood. A toxin produced by Yersina Pestis is carried from rodents to the human when the fleas bite the humans (History.Com Editor, 2010). This organism settled on the humans' lungs, the lungs' immune system will resist this foreign particle and the goblet cells will generate mucus or phlegm. Prolonged inflammation in the lung for more than 4 to 7 days, the lungs will eventually liquefy and generate bloody sputum. Patients were suffered from difficulty in breathing and suffocation. This eventually causes death. Rodents are considered pests which brings the Yersina pestis and caused Black Death. In fact, rodents are not the main cause of the disease if we apply the Theory of Changes. As we know all the creatures created by nature have holy duties. No exceptional to rodents. Rodents that are living near human beings are partially omnivorous and scavengers. They are created by Mother Nature to clean up the remaining food and animals' dead bodies left by human beings. This theory explains the existence of dogs and cats in human society as well. When humans know how to use fire, they have climbed up to the top of the food chain and eat most of the animals inclusive of those carnivores. In nature, most of the scavengers are living near to the habitat of the carnivores. For example, the hyenas and wild dogs would choose to live near the lions' habitat as they know that they could find the dead bodies left over by the lions. The same theory applies to the human being. When humans start eating meat and creating plenty of animals' dead bodies, they will attract the scavengers like dogs, cats, and rodents to live in their living environment. Their existence is to clean up the dead bodies.

Thus we should not treat rodents as a pest as they have their living purpose in nature. One realistic fact that we should accept is "Filthy condition attract rodents and flies and not the rodents and flies created the filthy condition." If we always keep our living environment clean and avoid those smelly food, the chances of flies and rodents enter into your house is relatively low. Rodents are the agents which help in decomposition. Even the bacteria and viruses living in the rodents' bodies are also having the same purpose of decomposing the animals' dead bodies awash in the human living environment. They are the cure for the environment and not the pests or diseases. The ancient drawing of rodents has a Hua (化) word in the stomach Hua (化) means transforming. It shows that the rodents could transform the animals' dead bodies and unwanted food remaining into excrements that are easier for the earth to absorb. The colonization of more microorganisms in the excrements of the rodents could also break down the toxic waste substances and turn into the harmless nutrient to be absorbed by the earth. In other words, they are performing the Pin Ma (牛马) duties in decomposing, transforming, filtration and purification. As mentioned before, humans' bodies are not designed to perform the decomposition and transforming process, the incapability has finally led to death.

The Coronavirus which causes Covid 19 is like other viruses using protein to latch onto and invade human cells. This virus is part of 
the RNA brigade of viruses which are much less stable than the DNA-based viruses. The instability in copying genetic code leads them to mutate easier and allows them to cross the huge division between different species. This makes the virus becomes more contagious and resistant to drugs. When encountering with the huge amount of the animals' dead bodies and pollutant, the Mother Earth need to create a more powerful and lethal virus to effectively settle the problems. Coronavirus attacks the human's lung and causes pneumonia where inflammation in the air sacs making the patient difficult to breathe. The deterioration of the condition without supporting care will probably lead to death. As we knew, the propagation of viruses either mitosis or meiosis depends on the specialized host cells to perform the complex metabolic and biosynthetic process. Metabolism is the biochemical processes that occur within a living organism which consists of anabolism (the buildup of substances) and catabolism (the breakdown of substances). The term metabolism is commonly used to refer specifically to the breakdown of food and its transformation into energy (Shiel Jr, 2018).

While biosynthesis in a living organism is a process in which substrates are converted to more complex products. Biosynthesis is usually synonymous with anabolism. The products which are produced as a result of biosynthesis are necessary for cellular and metabolic processes deemed essential for survival.

Catabolism is the breakdown of substances which is the decomposition process of Mother Earth, while anabolism is the buildup of substances which is the transformation process of Mother Earth to turn substances into useful energy or nutrients. Here we have to face the horrible facts that the Coronavirus is not a disease but a cure for Mother Earth and we are the virus for Mother Earth.

Human always blame that the animals or the insects (Entomopathogen) are the intermediate host for the contagious diseases. We kill them to prevent the outbreak but we never reflect upon ourselves that we are the root cause of the problem and not the innocent animals and insects. In fact, every living creature is the divine creation of Mother nature which has its holy duty and purpose. They are the members or agents of the Kun ( 坤) which assist in the Pin Ma ( 牝马 ) process. They are not the pest but the cure for ecological balance. The microorganisms that host on the animals' bodies are harmless to them. The pathogenic growths of the bacteria or viruses in the insect or animals are prevented by the host immune system, limitation of nutrients, or other competing microorganism parks inside their bodies. On contrary, certain microorganisms are found in the intestines of the animals could help the host to improve food digestion. The same as most of the E coli bacteria which are found in the human's and other warm blood animals' lower intestine could prevent the colonization of other pathogenic microorganisms and benefit the hosts by creating vitamin K2.

Thus the microorganism could be harmful to certain species and could be beneficial to another species. As we commonly acknowledge, a virus must use cell processes to replicate, and the viral replication cycle can produce dramatic biochemical and structural changes in the host cell, which may cause cell damage. These changes are called cytopathic (causing cell damage) effects, which can change cell functions or even destroy the cell (Lumen Learning, 2013).

A CT scan in COVID-19 extubated survivor: a study performed during recovery (26 days after onset of COVID-19 pneumonia). Image section at the level of the carina demonstrating widespread ground-glass opacification and considerable architectural distortion (George et al., 2020). In a longitudinal CT study of 90 patients with COVID-19, 94\% of individuals had residual changes on CT at discharge (median duration of 24 days after symptom onset) with ground-glass opacity the most common pattern (Wang et al., 2020).

At discharge, in a study of 110 patients with COVID-19, 91 (83\%) of whom had a mild-moderate disease and $19(17 \%)$ of whom had severe disease, almost half had impairment of the transfer factor of the lung for carbon monoxide (TLco) (Mo et al, 2020). Groundglass opacification/opacity (GGO) is a descriptive term referring to an area of increased attenuation in the lung. Architecture distortion is the result of the cell damage caused by the decomposition process being carried out by the Coronavirus.

The functional impairment of the lung has finally caused death. This damaging process is the decomposition process carried out by the virus. The microorganisms would be useful and beneficial if they were placed at the right time and in the right location. In short, the chances for us to acquire Covid 19 and other contagious diseases is relatively low if we don't allow the wrong microorganism to inhibit in our body and doing the unnecessary decomposition and transformation by adopting veganism and avoiding meat (animals' dead bodies) intake.

\section{Conclusion}

The destructive impact of animal agriculture and meat consumption culture on the environment and human health is undeniable. Meat industries are considered one of the prime causes contributing to the current six mass extinction. In the near decades, more than 10 thousands of animals will be on the brink of extinction. As we knew, all living beings inclusive humans, animals, plants, and other creations of nature should co-exist with 
each other in the protection and nourishment of Heaven and Earth The extinction and the destruction of any one of them will cause the ecological imbalance and lead to the breakdown of the process of Yuan, Heng, Li, Zhen (元亨利贞). The collapse of the Consolidated Yang and Harmonized Yin is unavoidable if the condition could not be neutralized and restored to the right order. At this verge of collapse, the Pin Ma (牝马) settlement has brought in by the Mother earth to prevent the deterioration of the equilibrium.

The lockdown of the whole world has brought a good rest to Mother Earth and her animal children. She is healing her wounds, taking a good rest, and breathing the sigh of relief, as well as her beloved children. During these socially isolated periods, many animals are enjoying temporary freedom and reclaiming their territories in the cities and villages. The endangered turtles in India and Brazil have been making the most of the deserted beaches to nest in peace. The pink jellyfishes which have been absent for years due to human activities are now flourishing beautifully along the coastline of Palawan, Philippines. Fishes and sea creatures are released back to the sea as demand dropped during the lockdown. The skies of most of the big cities in the world have turned blue as the carbon emission and pollution rate in the World were reduced at its utmost limit unprecedentedly.

Most importantly, the emerging of the Corona Viruses has substantially contributed to the decomposition and transformation of the overloaded dead bodies and animals' excrements into the useful elements which could be absorbed by Mother Earth. Given such a situation, we realized that the viruses are not the diseases but cure, and we are the virus to the planet which cause harm to the Mother Earth.

It is time for human to turn inward and reflect upon ourselves. What are the harms that we have done to our bodies, to the animals and to the mother earth? What are the sustainable lifestyle we should adopt for the good sake of our health, other earthlings and mother earth? The thorough evaluation by application of the Theory of Changes and the Yin and Yang Theory has proven that reduction in meat consumption and production could save us from being the victims of the process of decomposition and transformation of the viruses and other microorganism. After we have identified the deadly microorganism as the cure for Mother nature and recognize the harm that we have done to Mother Nature, we could find out the root cause of the problem and solve the problem fundamentally. The ecological balance of nature which has been damaged seriously by disruptive and excessive human activities needs to be settled with full dedication of the human being. Lockdown the whole world is not the appropriate long term approach. Humans should face the truth and solve the problem fundamentally. We could only gain peace and joy by giving peace and joy to Mother Nature and other living beings!

\section{REFERENCES}

Alonso Aguirre A, Richard Catherina, Hailey Frye, Louise Shelley (2020) Illicit Wildlife Trade, Wet Markets, and COVID-9: Preventing Future Pandemics. World Medical and Health Policy 12(3): 1-11. www.ncbi.nlm.nih.gov/pmc7362142/, 1,348.

Center For Disease Control and Prevention (2017) Zoonotic Diseases. https://www.cdc.gov/onehealth/basics/zoonoticdiseases.html. 1-5.

Dell'Anno A, Corinaldesi C, Danovaro R (2015) Virus decomposition provides an important contribution to benthic deepsea ecosystem functioning. National Library of Medicine.112 (16) : E2014-9. pubmed.ncbi.nlm.nih.gov.

George PM, Barratt SL, Robin Condliffe R, Desai SR, Devaraj A, et al. (2020) Respiratory follow-up of patients with COVID-19 pneumonia. https://thorax.bmj.com/content/75/11/1009.

History.com editors (2010) Black Death. Available at https://www.history.com/topics/middle-ages/black- death.UPD20. $1-4$

Kotwal GJ (2008) Genetic diversity-independent neutralization of pandemic viruses (e.g. HIV), potentially pandemic (e.g. H5N1 strain of influenza) and Carcinogenic (e.g. HBV and HCV) viruses and possible agents of bioterrorism (variola) by enveloped virus neutralizing compounds(EVNCs). Vaccine 26(24): 3055-3058. Sciencedirect.com/science/article/pii/S0264410X07014582.

Liang Yong Xuan, Lu Zhao Lin (2005) The Brief History of Traditional Chinese Medicine. China Press of Traditional Chinese Medicine. 5-6

Lumen Learning (2013) Virus Infections and Hosts/Biology II. Courses.lumenlearning.com/biology2xmaster/chapter/virusinfectious-and-hosts/

Matthew Zampa (2018) How Many Animals Are Killed for Food Every Day? Sentient Media. https://sentientmedia.org/how-manyanimals-are-killed-for-food-every-day/.

Mo X, Jian W, Su Z (2020) Abnormal pulmonary function in OVID-19 patients at time of hospital discharge. European Respiratory Journal 55: doi:10.1183/13993003.01217-2020.

News Strait Times (2020) Italy announces first Covid-19 death; cases rise to 17. https://www.nst.com.my. 
RNZ News (2020) Rapa Nui confirms second case of Covid-19. https://www.rnz.co.nz.

Shiel Jr WC (2018) Medical Definition of Metabolism. Medicine Net 1: 1. medicinenet.com.

Takao Y, Tomaru Y, Nagasaki K, Honda D (2015) Ecological Dynamics of Two Distinct Viruses Infecting Marine Eukaryotic Decomposer Thraustochytrids (Labyrinthuloncetes, Stramenopiles). PLoS ONE 10(7):e0133395.

Toshiko Kaneda, Charlotte Greenbaun, Kelly Kline (2020) 2020 World Population Data sheet shows older population rate growing, total fertility rate declining. PRB Data Sheet. 1:1. https://www.prb.org/2020-world-population-data.

Van Rensburg A, Van Straton J, Dekker J (2000) An in vitro investigation if the antimicrobial activity of oxifulvic acid. The Journal of Antimicrobial Chemotherapy $46: 853-854$.
Van Rensburg CEJ, Dekker J, Weis R, Smith TL, Rensburg EJ, Schneider J (2002) Investigation of anti-HIV properties of oxihumate. The Journal of Chemotherapy 48: 138-143.

Wang Qi Qing (2003) A study of The Yellow Emperor's Classic on Internal Medicine. China: The Chinese Medicine of China Publication. 1: 31-34.

Wang Y, Dong C , Hu Y (2020) Temporal changes of CT findings in 90 patients with COVID-19 pneumonia: a longitudinal study. Radiology 2020200843:200843. doi:10.1148/radiol.2020200843.

Xiongshi Kong, Yanyan Jia, Fuqiang Song, Kai Tian, et al. (2018) Insight into litter decomposition driven by nutrient demands of symbiosis system through the hypha bridge of arbuscular mycorrhizal fungi. Environmental Science and Pollution Research. 25(6):5369-5378 Pubmed.ncbi.nlm.nij.gov/29209973.

Yang Li (2010) The relationship between Zhou Yi and TCM. Beijing: Beijing Science and Technology Publication 2: 45-46. 